\title{
Field measurements of the attractivity of bypasses for fishfriendly trashrack
}

\author{
Fatma Lemkecher ${ }^{1}$, Laurent David $^{1}$, Dominique Courret $^{2}$, and Ludovic Chatellier ${ }^{1}$ \\ ${ }^{1}$ Institut Pprime, UPR3346, CNRS, Université de Poitiers, ENSMA, Bd Marie et Pierre Curie, Téléport 2, BP 30179, 86962 \\ Futuroscope, France \\ ${ }^{2}$ Agence Française de la Biodiversité, Pole Eco hydraulique, Institut de Mécanique des Fluides de Toulouse, Allée du \\ Professeur Camille Soula, 31400 Toulouse, France
}

\begin{abstract}
Fish-friendly trashracks, combining a low bar-spacing rack and bypasses, are a solution towards the fish downstream migration issue at hydroelectric intakes and rehabilitate the ecological continuity, as aimed by the European Water Framework Directive (2000). To comply to the French Environmental Code, the Hydropower plants (HPPs), located on rivers listed in list 2 according to the article L-214-17, must ensure an adequate sediment transport and free movement of fishes along the river. Each infrastructure has to be managed, and equipped according to the rules set by the administrative body in concertation with the owner or at least the operator. This study concerns inclined trashracks, which have an acute angle starting from the ground, to guide fishes to one of the surface bypass entrances. Well dimensioned bypasses should allow an efficient attraction of the fishes, while limiting the discharge in the bypasses that cause loss for hydraulic operators. In this context, a measurement campaign in a hydropower plant on the Ariège river has been carried out to characterize the velocity profiles at different positions upstream of a $26^{\circ}$ angle trashrack with an ADCP and the flow discharge of each of the 3 bypass entrances with flowmeter measurements. The measurements show that the streamwise velocities are quite homogeneous along the rack, without significant acceleration or deceleration, and that the tangential and normal velocities, $\mathrm{V}_{\mathrm{t}}$ and $\mathrm{V}_{\mathrm{n}}$, are consistent with their theoretical values. These results tend to validate the angular criteria proposed for inclined rack by Courret et Larinier [6] and studied experimentally by Raynal et al. [4] on a down-scaled model. However, it must be considered that the turbine discharge was low the day of measurement. So, these in situ measurements have to be conducted again, with a turbine discharge closed to its maximum.
\end{abstract}

\section{Introduction}

Hydroelectric facilities are well-established structures to provide sustainable energy but have been proven to be an obstacle for fish migration. Indeed, fishes are no longer free to migrate and, during downstream migration, they may be entrained through turbines and a part of them may suffer mortalities and injuries. In France, diadromous species such as European eels, sea trouts or salmon smolts are especially subjected to this impact [1; $2 ; 3]$.

Ecological continuity, including downstream migration of the species, has been identified as one of the hydromorphological elements which sustain the good ecological status of rivers, the goal of the European Water framework directive (2000/60/EC). One of the solutions developed to avoid the passage of fishes through the turbine is to install a fish-friendly trashrack combined with a bypass. These racks have a narrow bar spacing in order to stop fish and prevent them from entering into turbines and are inclined from the ground [4] or angled from the bank to guide fish towards bypasses, located at the most downstream end of the trashrack [5]. These trashracks therefore include a specific rack, whose parameters depend on river and intake characteristics (discharge, fish species, fish size), and one or several attractive bypass entrances, with suitable dimension and flow.

In France, in 2008, Courret et Larinier [6] defined criteria to design fishfriendly intake for smolts of Atlantic salmon and sea trout and for silver eels, clear spaces between bars $\leq 25 \mathrm{~mm}$ for smolts and $\leq 20 \mathrm{~mm}$ for silver 
eels are preconized to avoid the passage of fish through the rack. In case of inclined racks, fish must move vertically to reach one of the surface bypasses. To efficiently guide the fish, it's considered that the ratio of tangential to normal velocity components $\left(\mathrm{V}_{\mathrm{t}}\right.$ and $\mathrm{V}_{\mathrm{n}}$ respectively) at the trashrack, must be higher than 2 . The corresponding inclination angle $(\beta)$ may be first determined from a simple geometrical decomposition that results in $\beta \leq 26^{\circ}$. Moreover, this criterion is coupled with a maximum value for the normal component, related to fish swimming capacity, that is $V_{n} \leq 0.5 \mathrm{~ms}^{-1}$. These criteria related to the trashrack are also completed by other criteria related to the bypass entrances. In case of inclined racks, a minimum width of $1 \mathrm{~m}$ and a minimum water depth of $0.5 \mathrm{~m}$ are preconized to limit fish reticence and the entrance mean velocity should be close or slightly higher than the mean velocity magnitude. These criteria can be different in other countries and have to be adapted regarding local fish species.

Although a considerable feedback has already been acquired on the fishfriendly intakes, it remains necessary today to assess in situ intakes designed according to the latest recommendations, in terms of hydraulic and biological efficiency. This paper deals with in-situ measurements upstream of a trashrack inclined at $\beta=26^{\circ}$ at the hydropower plant of Las Rives. Normal and tangential velocity measurements are carried out using an ADCP and flow discharges in the bypasses are measured using a flowmeter. In the next section, the HPP will be presented followed by the description of the experimental devices. The last part will show the results and some discussion on the physical model measurements.

\section{Measurement Campaign:}

\subsection{Site description:}

The hydropower plant of Las Rives is located in the Ariège river, in the Commune de Varilhes and has an interannual discharge of $42 \mathrm{~m}^{3} \mathrm{~s}^{-1}$. It is composed of a headrace canal with $195 \mathrm{~m}$ length and a bypass reach of $550 \mathrm{~m}$ length. The maximum turbine discharge is $45 \mathrm{~m}^{3} \mathrm{~s}^{-1}$. The minimum instream flow in the bypassed reach is 4.6 $\mathrm{m}^{3} \mathrm{~s}^{-1}$. The species concerned by this HPP are salmon, see trout, lamprey, eel and brown trout.

Concerning the downstream migration, a trashrack (Figure 1) is located in the head of the headrace canal on the left bank, in order to integrate the downstream migration flow to the instream flow. The trashrack dimensions are an intake of $14 \mathrm{~m}$ width, a surface of $127 \mathrm{~m}^{2}$, an inclination of $26^{\circ}$, with rectangular profiled bars with a $20 \mathrm{~mm}$ spacing. Three bypass entrances are located at the top of the trashrack with entrance dimensions of $1 \mathrm{~m}$ width and $0.5 \mathrm{~m}$ height. The total bypass flow is $1.35 \mathrm{~m}^{3} \mathrm{~s}^{-1}$ ( $3 \%$ of the maximum turbine discharge). The rack surface between the bypass entrances is voluntary clogged over the same depth $(0.5 \mathrm{~m})$ to generate transversal velocities.

Given the rack angle and the clogging of the rack, the normal velocities $V_{n}$ should theoretically be equal to 0.5 the mean approach velocity $\mathrm{V}_{0}$ (equal to the ratio between the discharge and the intake area) and the tangential velocities $V_{t}$ should theoretically be close to $1 V_{0}$.

The intake is also equipped with a valve located at the foot of the rack in the right bank, to evacuate the accumulation of fine sediment. During the measurement, this valve was opened, due to some works in the HPP, in order, to maintain the minimum flow in the bypassed reach. This can influence the values of the velocities in its vicinity.

The 3 bypass entrances are connected to a common collection gallery whose section increase when getting closer in the downstream direction at each confluence with an entrance, as shown in Figure 1. Their total discharge is controlled by a rectangular weir at the downstream end of the collection gallery.

The turbine discharge during the measurement campaign was much lower $\left(15.2 \mathrm{~m}^{3} \mathrm{~s}^{-1}\right)$ than the maximum discharge $\left(45 \mathrm{~m}^{3} \mathrm{~s}^{-1}\right)$ due to low flow in the river. 

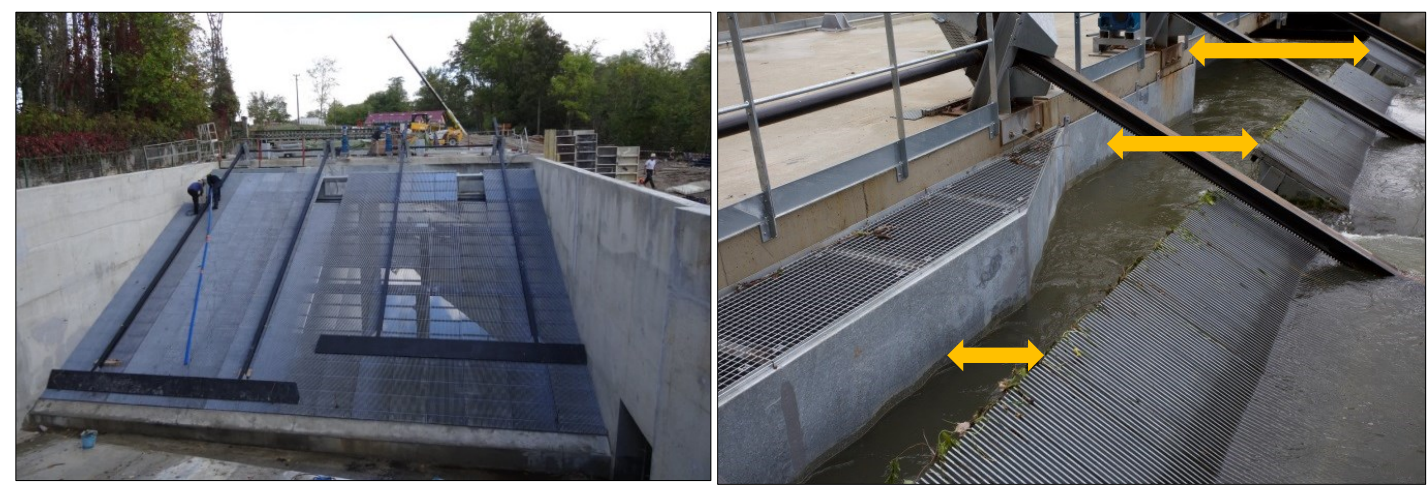

Figure 1: Trashrack out of water and downstream migration gallery
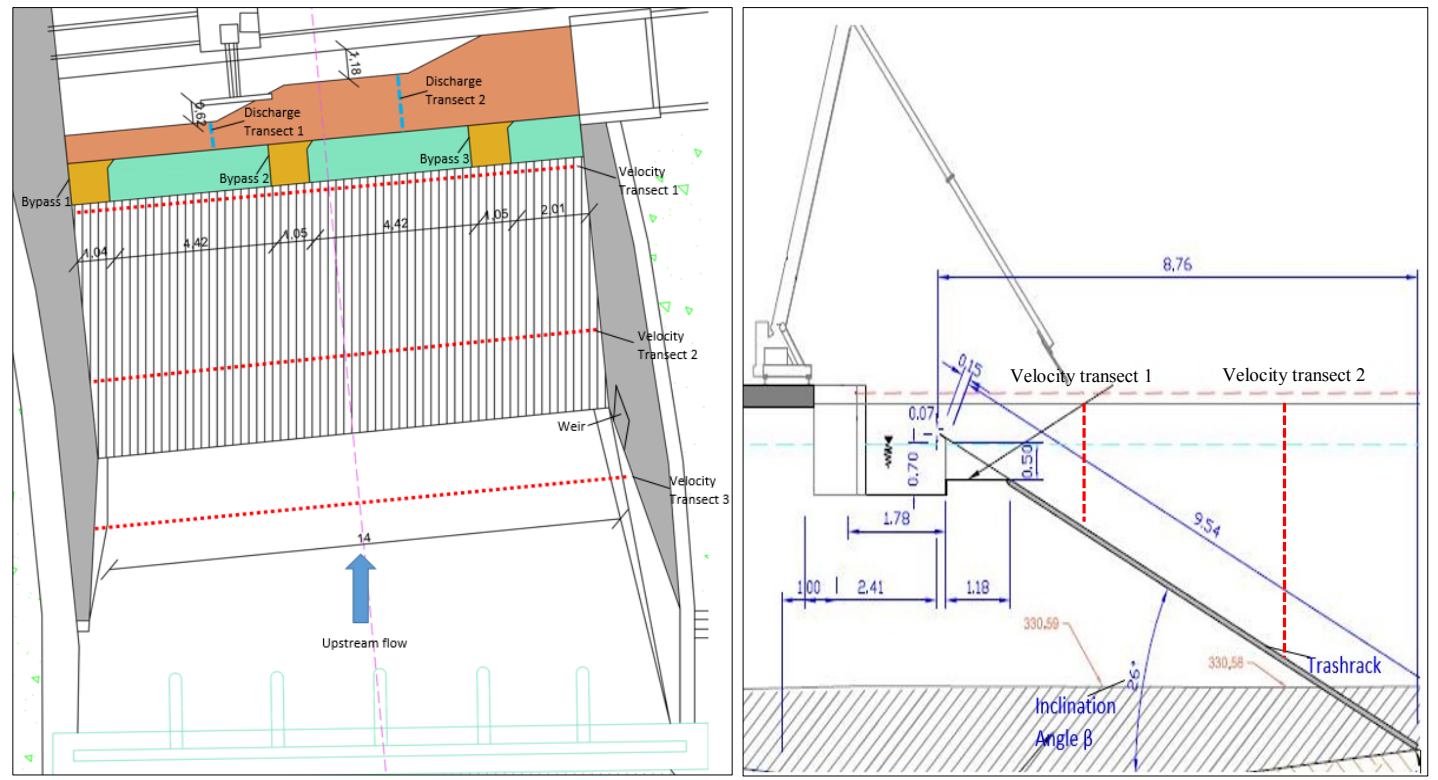

Figure 2: Trashrack and bypasses perspective and side plan with the transects of measurements

Figure 2 represents a perspective plan of the intake with the annotations of the trashrack and bypasses dimensions cited before. The red dashed lines schematize the three velocity transects that were investigated at -2 $\mathrm{m},-6 \mathrm{~m}$ and $-10 \mathrm{~m}$ upstream of the trashrack top end, respectively and the blue dashed lines are for the discharge transects.

\subsection{Experimental apparatus:}

The survey was conducted using a Teledyne StreamPRO Acoustic Doppler Current Profiler (Figure 3) which is a device that can provide vertical velocity profiles along river transects. The measurements were analyzed using the Teledyne Winriver II software. 


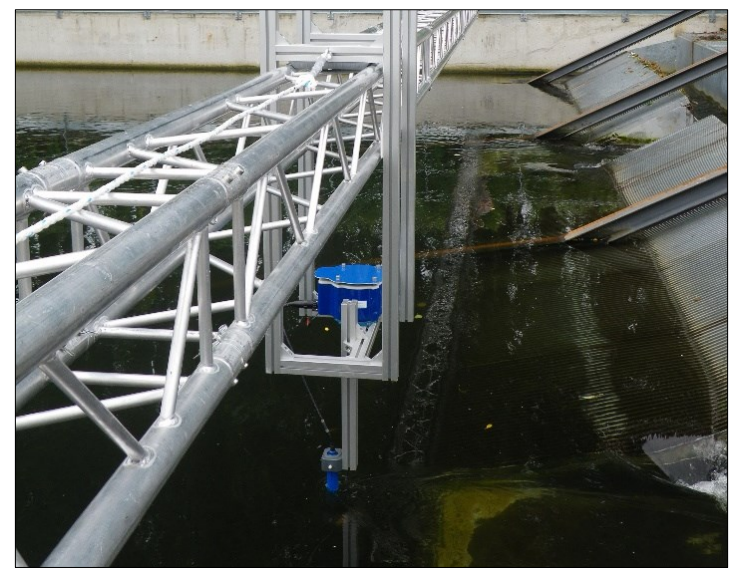

Figure 3: The Teledyne StreamPro ADCP Device

The different parameters such as the velocity components, the north and east displacement, the depth or the flow discharge are extracted for further processing and analysis. In practice, the first distance calculated using the east and north displacement, is projected according to the angle of the transect to provide the corresponding transverse position. Then, the north and east velocities values are projected to get the streamwise $\left(\mathrm{V}_{\mathrm{x}}\right)$, and transverse $\left(\mathrm{V}_{\mathrm{y}}\right)$ velocities, while the component $\mathrm{V}_{\mathrm{z}}$ is kept unchanged. The mean approach velocity, $\mathrm{V}_{0}$ is used for normalization.

The discharge gauging of the gallery downstream of the first and the second bypasses was obtained from the exploration of the velocity field with an electromagnetic flowmeter FLO-MATE 2000 (Marsh Mc Birney).The transects were located as far as possible from the upstream bypass to avoid turbulence and possible recirculation zones due to the flow junction, and keeping upstream the duct section modifications that may exist near the next bypass, with 5 verticals for the first section $(0.69 \mathrm{~m}$ width) and 7 verticals for the second section $(1.60 \mathrm{~m}$ width). As the velocity profile cannot be considered logarithmic inside the collection gallery, 6 velocity measurements are carried out along each vertical: at the bottom, at $20 \%, 40 \%, 60 \%$, and $80 \%$ depth from the bottom and at the surface. At each point, velocity measurements lasted 30 seconds.

The total discharge of the 3 bypasses was evaluated at the weir controlling the discharge with the classical formula of a rectangular weir, considering a discharge coefficient equal to 0.4 regarding the absence of lateral detachments (same width between the channel and the weir), with a correction due to the upstream kinetic energy.

\section{Results and discussions:}

Velocity maps are obtained for each velocity component at the three measurement sections along the trashrack.
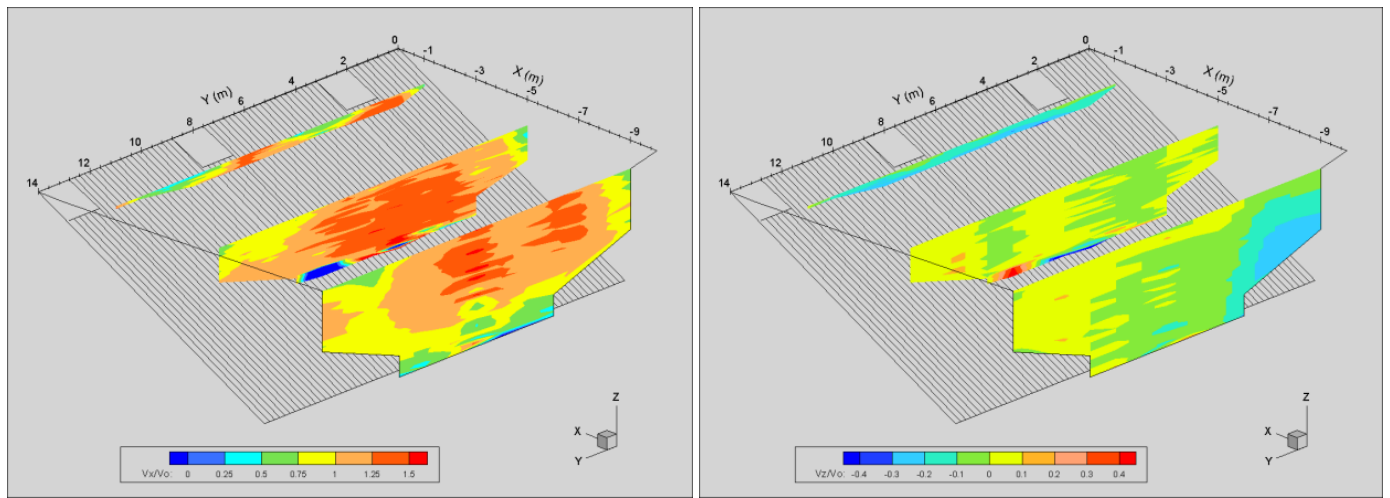

Figure 4: $V_{x} / V_{0}$ and $V_{z} / V_{0}$ velocity maps

Figure 4 shows the distribution of the normalized $\mathrm{V}_{\mathrm{x}}$ and $\mathrm{V}_{\mathrm{z}}$ velocities along the three sections of interest. Every section, globally, allows to visualize that the normalized $V_{x}$ tends to approach 1 , showing no significant 
acceleration or deceleration. At the top of the rack, normalized $V_{x}$ decrease between the bypass entrances as the rack is voluntary clogged and are higher than 1 in front of each entrance for $\mathrm{X}=-2 \mathrm{~m}$.

Compared to the normalized $V_{x}$ velocity distribution, figure 4 exhibits, also, a lower normalized $V_{z}$ velocity in the three measurement sections, which values are near to 0.25 . However, higher velocities are encountered at the bottom of the section located at $-6 \mathrm{~m}$ from the trashrack top.
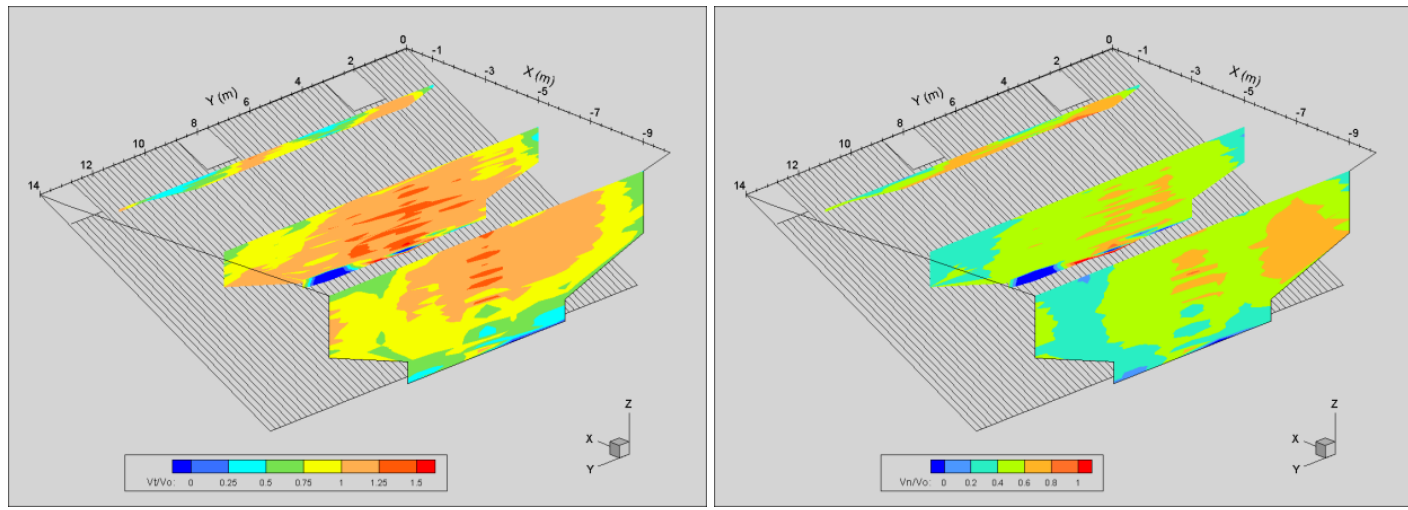

Figure 5: $\mathrm{V}_{\mathrm{t}} / \mathrm{V}_{0}$ and $\mathrm{V}_{\mathrm{n}} / \mathrm{V}_{0}$ velocity maps

Figure 5 describes normalized tangential and normal velocities, $V_{t}$ and $V_{n}$, at the three sections. The normalized $V_{t}$ stays close to unity while the normalized $V_{n}$ is mainly distributed around 0.5 . These results are consistent with the theoretical values.

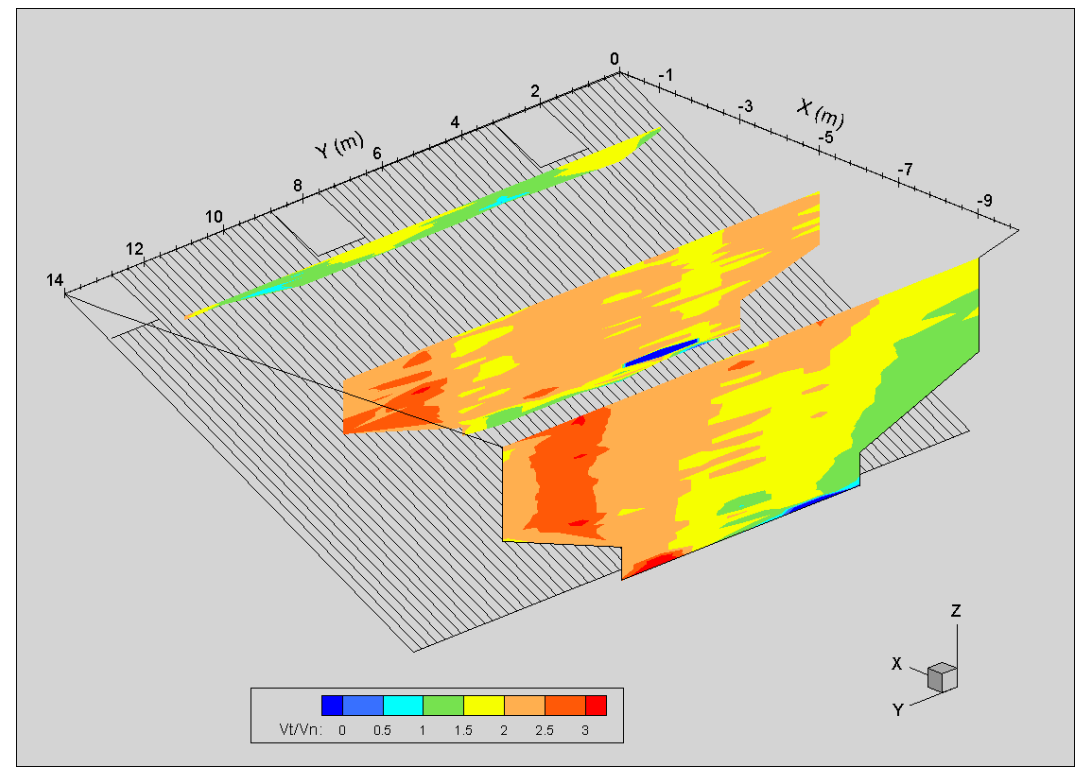

Figure 6: $V_{t} / V_{n}$ velocity map

Figure 6 represents the ratio between the normal and tangential velocities. Even if it can vary locally the measured ratio $V_{t} / V_{n}$ is mainly closed to 2 , which is consistent with the theoretical values. 


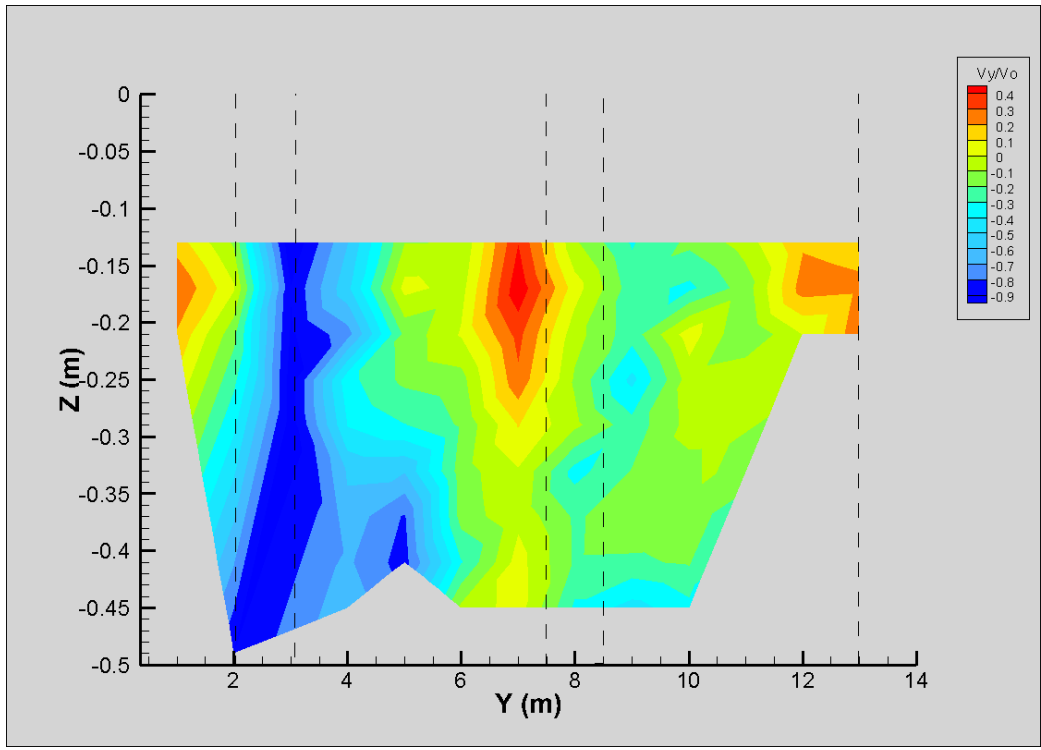

Figure 7: Normalized $V_{y}$ velocity map with the three bypasses in dashed lines at $X=-2 m$

Figure 7 represents a normalized $\mathrm{V}_{\mathrm{y}}$ velocity map at $\mathrm{X}=-2 \mathrm{~m}$ upstream the top of the trashrack. A positive value indicates a flow from the right to the left bank. The normalized velocity $\mathrm{V}_{\mathrm{y}}$ is higher than the reference velocity with a fraction near to 1.5 in some vertical areas. This shows the increase of the value of this velocity field upstream of the trashrack. The location of this rise is mostly at the bypass zone.

The respective discharge of the three bypass entrances are presented in the table below.

Table 1 : Bypass discharges

\begin{tabular}{|l|c|c|c|}
\hline & $\begin{array}{l}\text { Discharge } \\
\left(\mathbf{m}^{\mathbf{3}} \mathbf{- 1}\right)\end{array}$ & $\begin{array}{l}\text { Ratio from } \\
\text { the total } \\
\text { discharge }\end{array}$ & $\begin{array}{l}\text { Mean flow } \\
\text { velocity in the } \\
\text { bypass }\left(\mathbf{m s}^{-\mathbf{1}} \mathbf{)}\right.\end{array}$ \\
\hline Bypass 1 & 0.271 & $25.4 \%$ & 0.52 \\
\hline Bypass 2 & 0.360 & $33.7 \%$ & 0.69 \\
\hline Bypass 3 & 0.436 & $40.9 \%$ & 0.83 \\
\hline Total & 1.066 & $100.0 \%$ & \\
\hline
\end{tabular}

The day of measurement, the total bypass discharge $\left(1.06 \mathrm{~m}^{3} \mathrm{~s}^{-1}\right)$ was a bit lower than the theoretical value $\left(1.35 \mathrm{~m}^{3} \mathrm{~s}^{-1}\right)$, but represent roughly $7 \%$ of the turbine discharge $\left(15.2 \mathrm{~m}^{3} \mathrm{~s}^{-1}\right)$. The distribution of the total discharge is not perfectly balanced between the 3 entrances, despite the arrangement of the collection gallery (increasing width, deflector at the confluence). The most downstream entrance is favored at the expense of the most upstream entrance. However, such distribution is still satisfactory.

\section{Conclusion:}

Acoustic Doppler Current Profiler has been conducted along three transects upstream of the intake trashrack and migration bypasses of the Las Rives HPP on the Ariège river (France). This study provides data that allow characterizing the evolution of the velocity distribution upstream of a low inclined rack combined with threebypasses configuration, at a real scale HPP intake.

The measurements show that the streamwise velocities are quite homogeneous along the rack, without significant acceleration or deceleration, and that the tangential and normal velocities, $V_{t}$ and $V_{n}$, are consistent with their theoretical values. These results tend to validate the angular criteria proposed for inclined rack by Courret et Larinier [6] and studied experimentally by Raynal et al. [7] on a down-scaled model. However, it must be considered that the turbine discharge was low the day of measurement.

So, these in situ measurements have to be conducted again, with a turbine discharge closed to its maximum. 


\section{Acknowledgements}

This project has received funding from the European Union's Horizon 2020 research and innovation program FitHydro (www.fithydro.eu), under grant agreement No 727830 . We would like to thank ONDULIA, the hydroelectricity company, for their collaboration, the access to the water intake and the transmission of the operating data of the plant (www.ondulia.com).

\section{References}

1. Larinier M., Hydrobiologia, 609:97-108, (2008).

2. Travade F. and Larinier M., Proc. Int. Conf. International DWA symposium on water resources management, Berlin. Hennef, Germany, (2006).

3. Travade F., Larinier M., Subra S., Gomes P. and De-Oliveira E, Knowl. Manage. Aquatic Ecosyst, 398(1), 1-19 (2010).

4. Raynal S., Courret D., Chatellier L., Larinier M. and David L., Journal of Hydraulic Research, 51:1, 5666, (2013).

5. Raynal S., Courret D., Chatellier L., Larinier M. and David L., Journal of Hydraulic Research, 51:1, 6775, (2013).

6. Courret D. and Larinier M., ONEMA-ADEME, (2008).

7. Raynal S., Courret D., Chatellier L., Larinier M. and David L., Trondheim, Norway, 10th ISE (2014). 